\title{
Growth of polygonal rings and wires of CuS on structured surfaces
}

\section{Citation}

Vasquez, Yolanda, Erin M. Fenton, Victoria F. Chernow, and Joanna Aizenberg. 2011. "Growth of Polygonal Rings and Wires of CuS on Structured Surfaces." CrystEngComm 13 (4): 1077-1080. doi:10.1039/c0ce00499e.

\section{Published Version}

doi:10.1039/COCE00499E

\section{Permanent link}

http://nrs.harvard.edu/urn-3:HUL.InstRepos:34903212

\section{Terms of Use}

This article was downloaded from Harvard University's DASH repository, and is made available under the terms and conditions applicable to Open Access Policy Articles, as set forth at http:// nrs.harvard.edu/urn-3:HUL.InstRepos:dash.current.terms-of-use\#OAP

\section{Share Your Story}

The Harvard community has made this article openly available.

Please share how this access benefits you. Submit a story.

\section{Accessibility}




\title{
Growth of polygonal rings and wires of $\mathrm{CuS}$ on structured surfaces
}

\author{
Yolanda Vasquez, ${ }^{a, b}$ Erin M. Fenton, ${ }^{c}$ Victoria Chernow, ${ }^{a}$ and Joanna Aizenberg ${ }^{* a, b, d}$
}

Polygonal rings and microwires of covellite-type $\mathrm{CuS}$ were grown on micropillar arrays using chemical bath deposition and characterized by SEM, TEM, and XRD. A growth mechanism involving heterogeneous nucleation of $\mathrm{CuS}$ spheres at the micropillar tips, followed by their selfassembly into wires, is proposed.

Copper sulfides have been studied for many years as potential materials for optoelectronic devices and for applications in photovoltaics. ${ }^{1}$ The stoichiometric factor of these materials varies between 1 and $2\left(\mathrm{Cu}_{2-x} \mathrm{~S}\right)$ due to copper vacancies within the lattice, which influence their electronic properties. $^{2}$ These materials exhibit dependence of their bandgap in the bulk on the stoichiometry, ranging from $\mathrm{Eg}=1.2 \mathrm{eV}$ for chalcocite $\left(\mathrm{Cu}_{2} \mathrm{~S}\right), 1.5 \mathrm{eV}$ for digenite $\left(\mathrm{Cu}_{1.8} \mathrm{~S}\right.$, ) to 2.0 for covellite $(\mathrm{CuS}){ }^{3}$ Applications of these materials span from photovoltaics, ${ }^{4,5}$ superionic materials, ${ }^{6}$ to chemical sensing. ${ }^{7}$ Due to these promising applications, several synthetic methods have been developed to produce nanoscale and micron scale $\mathrm{Cu}_{2-x} \mathrm{~S}$ materials including decomposition reactions, ${ }^{8,9}$ hydrothermal, ${ }^{10}$ microemulsions, ${ }^{11}$ thin films, ${ }^{12}$ and electrochemical/electroless deposition. ${ }^{13,14}$ However, control over composition, shape, and impurities remains a challenge. The synthetic conditions determine the stoichiometry, crystallinity, and morphology, all of which significantly affect the bandgap. Reports of shape controlled morphologies of copper sulfides are numerous and include nanorods, ${ }^{15}$ dendrites, ${ }^{16}$ nanodisks, ${ }^{17}$ nanoplatelets, ${ }^{18}$ snowflakes, ${ }^{19}$ nanowalls, ${ }^{20}$ flowers and hollow spheres. ${ }^{21}$

In particular, rings have received a lot of attention because of their applications in nanoelectronics, ${ }^{22}$ optoelectronics, ${ }^{23}$ and energy conversion. ${ }^{24}$ Controlled kinking and ring for-

\footnotetext{
a Department of Chemistry and Chemical Biology, Harvard University, Cambridge, MA, USA. E-mail: xxxx@aaa.bbb.ccc

$b$ School of Engineering and Applied Sciences, Harvard University, Cambridge, MA, USA.

${ }^{c}$ Center for Biomedical Engineering and Department of Chemical and $\mathrm{Nu}$ clear Engineering, University of New Mexico, Albuquerque, NM, USA.

$d$ Wyss Institute for Biologically Inspired Materials, Harvard University, Cambridge, MA, USA.

*E-mail: jaiz@seas.harvard.edu
}

mation has been achieved for some semiconducting materials such as $\mathrm{ZnO},{ }^{25}, \mathrm{SnO}_{2},{ }^{26} \mathrm{In}_{2} \mathrm{O}_{3},{ }^{27} \mathrm{Zn}_{2} \mathrm{GeO}_{4},{ }^{27}$ and $\mathrm{Si}^{28}$ using vapor liquid solid growth and vapor solid growth. Interestingly, nanorings and nanowires of a conducting polymer, polyaniline, were reported to grow on hydrophobic selfassembled monolayers (SAM) and $\beta$-cyclodextrins using electroless deposition. ${ }^{29}$ Similarly, polyaniline nanowires were grown on silica colloids ${ }^{30}$ and textured surfaces ${ }^{31}$ with good control over the diameter of the nanowires. This approach was determined to be applicable to inorganic materials, such as $\mathrm{ZnO},{ }^{30,32}$ but has not been widely applied to other semiconductor materials.

Here, we report the synthesis of polygonal rings and micronscale wires of covellite-type copper sulfide $(\mathrm{CuS})$ grown on structured surfaces bearing an array of micropillars using electroless deposition (Fig. 1). To our knowledge, the unique morphology of these micron-sized $\mathrm{CuS}$ polygonal rings has not been reported in the literature. By introducing a structured surface into the hydrothermal synthesis of $\mathrm{CuS}$, we provide a microenvironment with a high density of nucleation sites and limited crystal growth surface. The crystalline particles growing solely at the tips of the pillars assemble into a "beaded" string that either assumes polygonal shapes or grows into an extremely long crystalline microwire. Using this strategy, it may be possible to precisely control the resulting polymorphs, particle size, crystallinity, morphology, crystallographic orientation, composition, stability and hierarchical assembly of other technologically relevant crystalline materials.

The microenvironments for crystallization of $\mathrm{CuS}$ were made by using an etched $\mathrm{Si}$ master with a square array of micropillars ( $1 \mu \mathrm{m}$ diameter, $8 \mu \mathrm{m}$ length, and $3 \mu \mathrm{m}$ pitch), replicating these structures using soft lithography, and subsequently molding the structures in epoxy (see Methods). Epoxy replicas were then rendered superhydrophobic by sputtering the surface with $\mathrm{Pt} / \mathrm{Pd}$ and functionalizing with a SAM of 1heptanethiol. The replicas were placed in a chemical bath containing aqueous solution of copper sulfate and sodium thiosulfate at concentrations of $0.01 \mathrm{M}$. Hexagonal rings of $\mathrm{CuS}$ were formed after $3 \mathrm{~h}$ upon immersing the substrate in the salt solution (Fig. 1a). The most commonly observed morphology was hexagonal particles that formed closed or opened rings with angles $\sim 120^{\circ}$ for closed hexagons and between $110-130^{\circ}$ for 


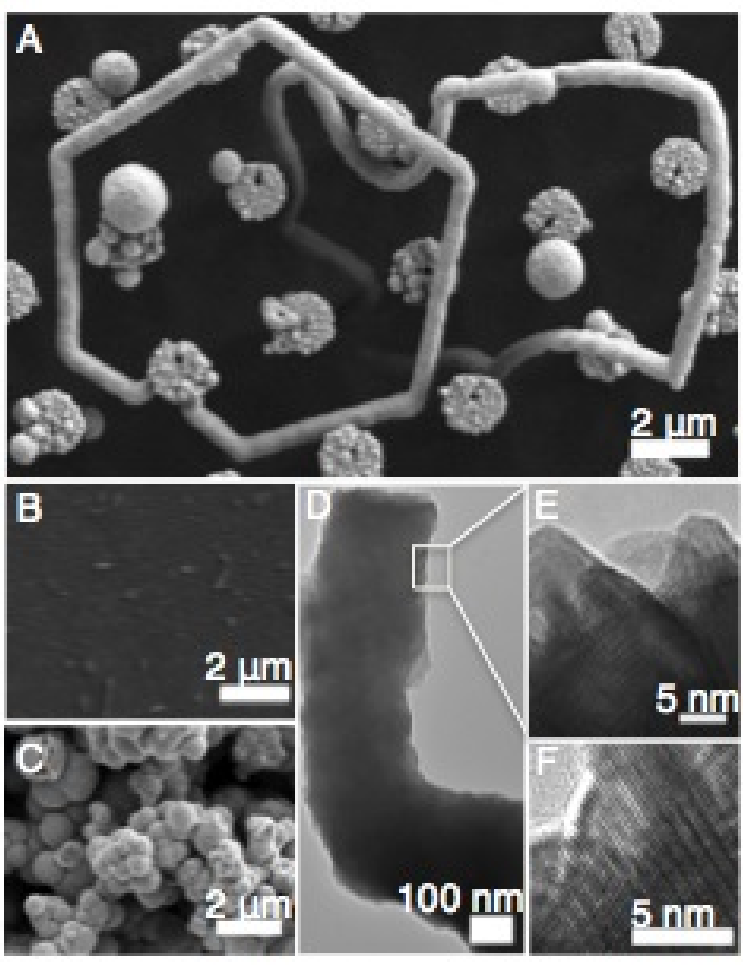

Fig. 1 a) Representative SEM image of hexagonal CuS particles grown on the tips of a micropillar array using electroless deposition; b) SEM image of CuS film deposited on flat epoxy; c) SEM image of particles nucleated in solution; d) TEM image of hexagonal particle; e) High magnification TEM image depicting polycrystalline structure of CuS hexagonal particle; f) TEM image of lattice fringes with d-spacing $2.71 \AA$ that corresponds to $\{006\}$ planes of covellite-type $\mathrm{CuS}$.

open/irregular polygons. The resulting rings exhibited sharp edges when kinked on the surface of the pillars, while they were more rounded when formed below the tips of the pillars. The polygonal rings were on average $600 \mathrm{~nm}$ in diameter, with the perimeter varying from 30 to $44 \mu \mathrm{m}$, consistent with measured line segments which are $\sim 5 \mu \mathrm{m}$. Control experiments involving crystallization of $\mathrm{CuS}$ on flat epoxy substrates with Pt/Pd coating and functionalized with hydrophobic 1-heptanethiol SAM resulted in no hexagonal/polygonal structures (Fig. 1b). In these control experiments, precipitation of spherical particles from the bulk solution occurred, indicating that the formation of polygonal rings is templated by the microstructured surface (Fig. 1c).

TEM images show that the hexagons/polygons consist of many loosely attached crystallites (Fig. 1d, e). The lattice spacing was found to be $2.71 \AA$ by TEM, which corresponds to the $\{006\}$ planes of covellite type $\mathrm{CuS}\left(\mathrm{P}_{3} / \mathrm{mmc}\right)$ (Fig. 1e-f). The polycrystalline nature of these structures and the well de-

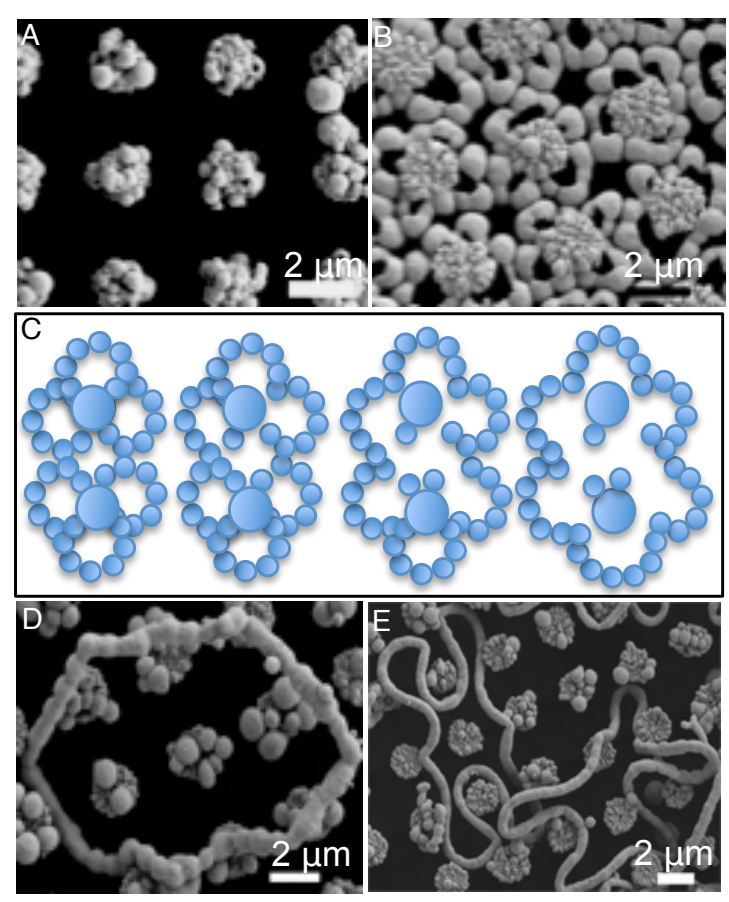

Fig. 2 a) CuS spherical particles nucleating on tips of pillars; b) $\mathrm{CuS}$ particles growing around micropillars; c) Step-wise depiction of chain-like assemblies of $\mathrm{CuS}$ polygons forming and detaching; d) hexagonal morphology of $\mathrm{CuS}$ ring formed by fused $\mathrm{CuS}$ particles; e) smooth rings with little evidence of spherical aggregates, conform to the confining pillars.

fined morphology with $\sim 120^{\circ}$ angles suggests that the hexagonal rings form via an oriented attachment mechanism analogous to the mesocrystal formation in biomimetic/biogenic systems. ${ }^{33,34}$ It has been shown that mesocrystals can form not only by the inclusion of small molecules between the crystallites, but their formation can also be induced by impurities such as a secondary phase or through the transformation from the amorphous phase. ${ }^{33,34}$ Kinks and $120^{\circ}$ angles can also result from space group considerations; the $\langle 11-20\rangle$ or $\langle 1-100\rangle$ vectors could result in the desired kinks when rotating about the $\langle 0001\rangle$ zone axis. ${ }^{28}$ The hexagonal shapes/polygons may be a kinetic intermediate in the crystallization path of covellite-type $\mathrm{CuS}$, which is stabilized by the micro-structured surface.

In order to understand the mechanism of the formation of these unique polygonal rings, we have performed the analysis of the precipitation products and morphologies at different stages of development (Fig. 2). It is worth noting that the coated epoxy substrate is superhydrophobic. The hydrophobic nature of the surface helps form the rings since the crystallization solution only wets the tips of the posts, which serve as highly localized nucleation sites. At an early stage (30 min), 


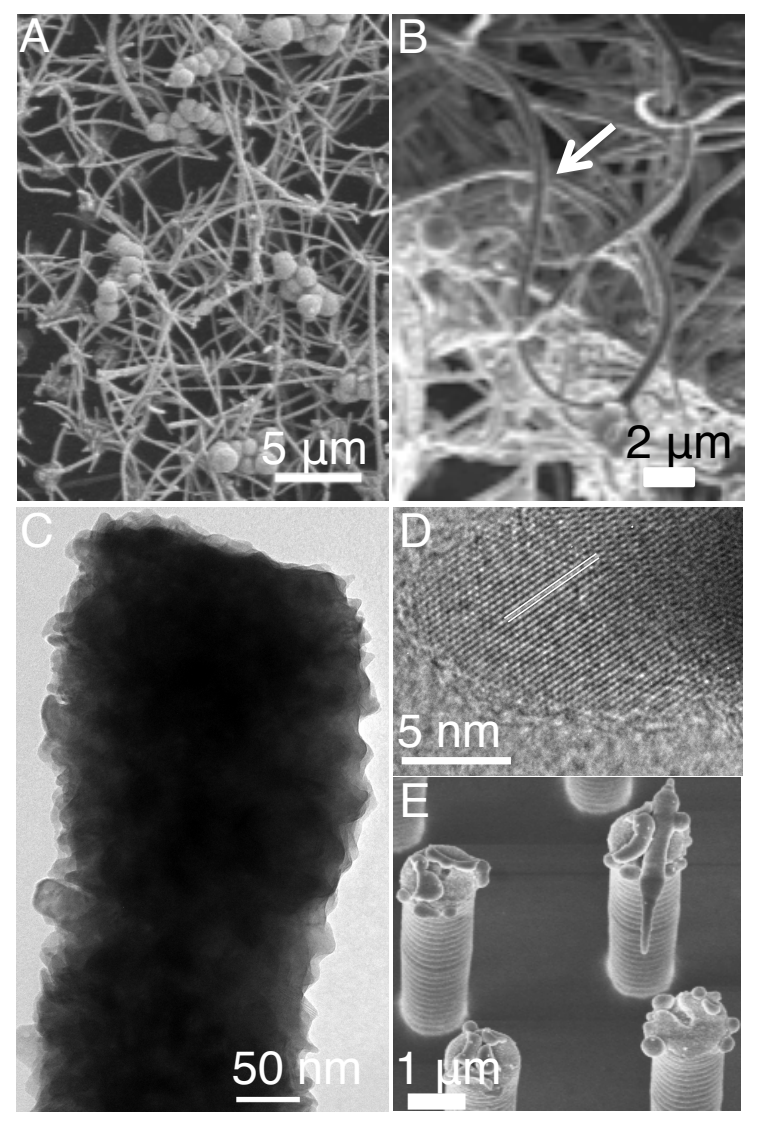

Fig. 3 a) SEM image of large area $\mathrm{CuS}$ nanowires grown on micropillar arrays; b) SEM image depicting highly flexible nanowires; c) TEM image of polycrystalline nanowire; d)TEM image depicting lattice fringes with d-spacing $2.71 \AA$ which corresponds to $\{006\}$ planes of covellite-type $\mathrm{CuS}$; e) SEM image of $\mathrm{CuS}$ nanowire nucleating on the tip of a micropillar.

$\mathrm{CuS}$ spheres nucleate on the tips of the posts (Fig. 2a). As these spheres grow (1h), they touch, begin to fuse, and form chains of particles in the form of "petals" connected to the central pillar (Fig. 2a, b). Upon further growth, the chains of spheres become too large for the space between the pillars and detach from the tips of the pillars and reconnect with the neighboring chains (Fig. 2c). Because the chains form around the pillars, it is evident that the polygons would eventually form closed chain of microbeads (Fig. 2d). The structured surface provides a physical barrier that helps to form the polygonal strings of particles and chemical gradient that allows for the self-assembly of particles (Fig. 2d). Over time, the outer surface of the hexagonal/polygonal rings becomes smooth and the chains reconnect into longer wires (Fig. 2e).

At higher apparent concentrations, the superhydrophobic nature of these substrates allows for only the tips of the pillars to serve as nucleation sites when exposed to the aqueous

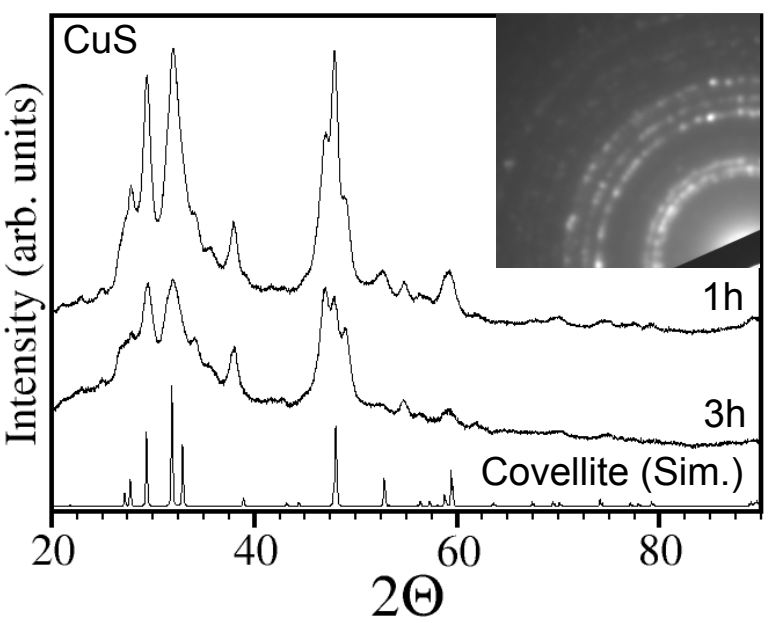

Fig. $4 \mathrm{XRD}$ patterns of $\mathrm{CuS}$ formed after $1 \mathrm{~h}$ and $3 \mathrm{~h}$ reaction times which correspond to covellite-type $\mathrm{CuS}$. The electron diffraction pattern (inset) taken from a polygonal particle is also consistent with covellite type $\mathrm{CuS}$ (JCPDS-79-2321).

chemical bath, resulting in the formation of wires (Fig. 3a, b). Sizes of the wires vary from 250 to $350 \mathrm{~nm}$ in diameter and more than $20 \mu \mathrm{m}$ in length. These $\mathrm{CuS}$ wires have, therefore, an extremely high aspect ratio, which is difficult to achieve with solution techniques. Although these crystalline chains are not mono-disperse, it is rare that such a tight size distribution of wires is achieved in solution without the use of stabilizers, polymers, or surfactants. Unlike the hexagonal rings, the wires grow within 30 min from the start of the chemical reaction up to $12 \mathrm{~h}$. These wires, like the hexagonal polygons formed at lower concentration, are composed of crystallites that self-assemble into a long chain (Fig. 3c). The crystals are covellite-type $\mathrm{CuS}$ (hexagonal) based on the measured lattice spacing (Fig. 3d). SEM images of early stages of the reaction $(20 \mathrm{~min})$ show that the nanowires nucleate on the tips of the pillars (Fig. 3e). X-ray diffraction studies of the precipitate at $1 \mathrm{~h}$ and $3 \mathrm{~h}$ verify that covellite is indeed the predominant crystalline phase and are consistent with the representative electron diffraction pattern taken from the hexagonal particle (Fig. 4).

In conclusion, this work has shown that a substrate bearing superhydrophobic micropillar arrays can be used as a patterned array of sites for heterogeneous nucleation of $\mathrm{CuS}$ crystallites with highly unusual morphologies. In particular, kinked polygonal microwires and serpentines $250-350 \mathrm{~nm}$ in diameter and tens of microns in length were formed. X-ray diffraction and selected area electron diffraction studies confirmed that the products were hexagonal type $\mathrm{CuS}$, or covellite, in all cases. We show that the mechanism of the formation of these structures involves (i) localized nucleation of $\mathrm{CuS}$ spheres at the tips of the pillars that are selectively wet- 
ted by the crystallization solution, (ii) fusion of the particles into chains connected to the micropillars, and (iii) release of the chains from the posts upon growth and their reconnection with the chains emerging from the neighboring pillars. Interestingly, the resulting kinked wires, polygonal rings, and long serpentines formed without aid from additional surfactants, suggesting that the self-assembly may occur through an oriented attachment mechanism, with hexagonal rings being only an intermediate in the crystallization pathway. We believe that this new templating approach that leads to the formation of nano- and microwires from solution can be applied for crystallization of a broad range of inorganic materials, and work is underway to expand this to other sulfides including $\mathrm{CdS}$ and $\mathrm{PbS}$.

\section{Notes and references.}

Chemicals $\mathrm{CuSO}_{4}$ (anhydrous) $99 \%, \mathrm{Na}_{2} \mathrm{~S}_{2} \mathrm{O}_{3}$, were purchased from Sigma-Aldrich (St. Louis, MO). Polydimethylsiloxane (PDMS; Dow Sylgard 184) was purchased from Ellsworth (Germantown, WI). Epoxy OG142 was purchased from Epoxy Technology (Billerica, MA). All chemicals were used as received. Methods Silicon masters of the post arrays were fabricated using the Bosch process as described elsewhere. ${ }^{35} \mathrm{~A}$ silicon master with features consisting of microscale posts with $1 \mu \mathrm{m}$ diameter, $8 \mu \mathrm{m}$ length, and $3 \mu \mathrm{m}$ pitch was used for all experiments. A double replication technique was used to produce the final OG- 142 epoxy samples. ${ }^{36}$ Epoxy OG-142 replicas were rendered superhydrophobic by sputter coating with $\mathrm{Pt} / \mathrm{Pd}(20 \mathrm{~nm})$ and growing a self assembled monolayer (SAM) of 1-heptanethiol in vacuo (contact angle $155^{\circ}$ ). The hydrophobic $\mathrm{Pt} / \mathrm{Pd}$ coated epoxy mold was then placed vertically using a clamp in a chemical bath containing aqueous solutions of $\mathrm{CuSO}_{4}$ and $\mathrm{Na}_{2} \mathrm{~S}_{2} \mathrm{O}_{3}$. The reaction mixture was then heated to $50^{\circ} \mathrm{C}$ for $1-12$ hours. The substrate was then rinsed in $\mathrm{DI}_{2} \mathrm{O}$ and dried under ambient conditions. The precipitate was collected by centrifugation, washed in $\mathrm{DI}_{2} \mathrm{O}$ and ethanol, and kept for further characterization. The synthesis of $\mathrm{CuS}$ was performed following a modified procedure published by Gadave et al. ${ }^{14}$ Rings and wires were synthesized using chemical bath deposition with concentrations of $0.01 \mathrm{M} \mathrm{CuSO}_{4}$ and 0.01 $\mathrm{M} \mathrm{Na}_{2} \mathrm{~S}_{2} \mathrm{O}_{3}$ in $100 \mathrm{~mL}$ of DI $\mathrm{H}_{2} \mathrm{O}$. The $\mathrm{pH}$ of the solution was adjusted to 5 . Characterization of particles was performed on a JEOL 2010 FETEM operated at $200 \mathrm{KV}$ and a Zeiss Ultra 55 FESEM. Crystallinity and phase purity were determined by X-ray diffraction using Scintag XDS2000 powder diffractometer.

Acknowledgements Y. V. would like to thank Mary Fieser Postdoctoral Fellowship. This work was supported by the Nanoscale Science and Engineering Center (NSEC) (NSF-PHY06-46094). E. M. F. thanks the NSF UNM/ Harvard PREM grant.

\section{References}

1 K. L. Chopra and S. R. Das, Thin Film Solar Cells, Springer, New York, 1983.

2 L. D. Partain, P. S. McLeod, J. a. Duisman, T. M. Peterson, D. E. Sawyer and C. S. Dean, J. Appl. Phys., 1983, 54, 6708.

3 D. Koch and R. Mcintyre, J. Electroanal. Chem., 1976, 71, 285-296.

4 Y. Lou, A. C. S. Samia, J. Cowen, K. Banger, X. Chen, H. Lee and C. Burda, Phys. Chem. Chem. Phys., 2003, 5, 1091-1095.

5 L. Reijnen, B. Meester, A. Goossens and J. Schoonman, Chem. Vap. Deposition, 2003, 9, 15-20.

6 M. K. Balapanov, I. B. Zinnurov and U. K. Mukhamedyanov, Russ. J. Electrochem., 2007, 43, 585-589.
7 S. Zhang, H. Zhong and C. Ding, Anal. Chem., 2008, 80, 7206-7212.

8 T. H. Larsen, M. Sigman, A. Ghezelbash, R. C. Doty and B. A. Korgel, J. Am. Chem. Soc., 2003, 125, 5638-9.

9 W. P. Lim, C. T. Wong, S. L. Ang, H. Y. Low and W. S. Chin, Chem. Mater, 2006, 18, 6170-6177.

10 Y. Zhao, H. Pan, Y. Lou, X. Qiu, J. Zhu and C. Burda, J. Am. Chem. Soc., 2009, 131, 4253-61.

11 P. Zhang and L. Gao, J. Mater. Chem., 2003, 13, 2007.

12 M. Nair, L. Guerrero and P. Nair, Semicond. Sci. Technol., 1998, 13, 1164-1169.

13 E. Fatas, T. Garcia, C. Montemayor, A. Medina, E. Camarero and F. Arjona, Mater. Chem. Phys., 1985, 12, 121-128.

14 K. Gadave and C. Lokhande, Thin Solid Films, 1993, 229, 1 - 4.

15 B. Sadtler, D. O. Demchenko, H. Zheng, S. M. Hughes, M. G. Merkle, U. Dahmen, L.-W. Wang and A. P. Alivisatos, J. Am. Chem. Soc., 2009, 131, 5285-93.

16 Z. Fang, X. Wang, J. Shen, X. Lin, Y. Ni and X. Wei, Cryst. Growth Des., 2010, 10, 469-474

17 Y. Wang, Y. Hu, Q. Zhang, J. Ge, Z. Lu, Y. Hou and Y. Yin, Inorg. Chem., 2010, 49, 6601-6608.

18 W. Du, X. Qian, X. Ma, Q. Gong, H. Cao and J. Yin, Chem. Eur. J., 2007, 13, 3241-7.

19 Z. Wu, C. Pan, Z. Yao, Q. Zhao and Y. Xie, Cryst. Growth Des., 2006, 6, 1717-1719.

20 X. Feng, Y. Li, H. Liu, Y. Li, S. Cui, N. Wang, L. Jiang, X. Liu and M. Yuan, Nanotechnology, 2007, 18, 145706.

21 B. Li, Y. Xie and Y. Xue, J. Phys. Chem. C, 2007, 111, 12181-12187.

22 W. Lu and C. M. Lieber, Nat. Mater., 2007, 6, 841-50.

23 X. F. Duan, Y. Huang, R. Agarwal and C. M. Lieber, Nature, 2003, 421, 241-245.

24 M. J. Bierman and S. Jin, Energy Environ. Sci., 2009, 2, 1050.

25 X. Y. Kong, Y. Ding, R. Yang and Z. L. Wang, Science (New York, N.Y.), 2004, 303, 1348-51.

26 Y. Lilach, J.-P. Zhang, M. Moskovits and A. Kolmakov, Nano letters, $2005,5,2019-22$.

27 C. Yan, N. Singh and P. S. Lee, ACS nano, 2010, 4, 5350-6.

28 B. Tian, P. Xie, T. J. Kempa, D. C. Bell and C. M. Lieber, Nat. Nanotechnol., 2009, 4, 824-9.

29 S.-J. Choi and S.-M. Park, Adv. Mater, 2000, 12, 1547-1549.

30 J. Liu, Y. Lin, L. Liang, J. A. Voigt, D. L. Huber, Z. R. Tian, E. Coker, B. McKenzie and M. J. McDermott, Chem. Eur. J., 2003, 9, 604-11.

31 N.-R. Chiou, C. Lu, J. Guan, L. J. Lee and A. J. Epstein, Nat. Nanotechnol., 2007, 2, 354-7.

32 Z. R. Tian, J. a. Voigt, J. Liu, B. McKenzie, M. J. McDermott, M. a. Rodriguez, H. Konishi and H. Xu, Nat. Mater, 2003, 2, 821-6.

33 H. Cölfen and M. Antonietti, Angew. Chem. Int. Ed., 2005, 44, 5576-91.

34 M. Niederberger and H. Cölfen, Phys. Chem. Chem. Phys., 2006, 8, 327187.

35 T. N. Krupenkin, J. A. Taylor, T. M. Schneider and S. Yang, Langmuir, 2004, 20, 3824-7.

36 B. Pokroy, A. K. Epstein, M. C. M. Persson-Gulda and J. Aizenberg, Adv. Mater., 2009, 21, 463-469. 